Conclusion A high fruit and vegetable intake may help preserve cognitive function in the elderly, but education is a powerful confounder and may play an important role, especially in a lowincome population.

\section{P2-237 $\beta$-CAROTENE IS ASSOCIATED WITH REDUCED RISK OF COGNITIVE FUNCTION IN LOW- INCOME ELDERLY FROM SãO PAULO, BRAZIL}

doi:10.1136/jech.2011.142976j.70

${ }^{1} \mathrm{M}$ Pastor-Valero, ${ }^{*} \mathrm{R}$ Furlan-Viebig, ${ }^{2} \mathrm{P}$ R Menezes, ${ }^{3} \mathrm{M}$ Scazufca. ${ }^{1}$ Departamento de Salud Pública, Facultad de Medicina, Universidad Miguel Hernández, Campus San Juan, Sant Joan d'Alacant, Spain; ${ }^{2}$ Departamento de Medicina Preventiva, Faculdade de Medicina, Universidade de São Paulo, São Paulo, Brazil; ${ }^{3}$ nstituto e Departamento de Psiquiatria da Faculdade de Medicina, Universidade de São Paulo, São Paulo, Brazil

Introduction The influence of individual antioxidant vitamins on cognitive function in older adults remains uncertain. Randomised trials of dietary interventions have yielded mixed findings. We examined the relation between dietary carotenoids and vitamin $\mathrm{C}$ intake from fruit and vegetables and the cognitive function of a lowincome population from Sao Paulo.

Methods Cross-sectional analyses of 1849 elderly $\geq 65$ years old, free of dementia, at the baseline of the SPAH study. We estimated the usual intake of vitamin $\mathrm{C}, \alpha$-carotene, $\beta$-carotene, $\beta$-cryptoxanthin, lycopen, luthein and zeoxanthin by means of a Willet-like FFO. Cognition function was assessed using the Community Screening Instrument for Dementia (CSI-D) (scored as 0-30). Few cases with score $=0$ were excluded. The association between cognitive function and the intake of each antioxidant was investigated using multiple linear regression models.

Results After adjusting for age, gender, education, per capita income, physical activity, HDL-cholesterol, hypertension, stroke, smoking, alcohol consumption and BMI higher $\beta$-carotene intake was associated with higher cognitive function scores $(\beta=0.2 ; 95 \%$ CI 0.1 to 0.3 ; $p<0.001$ for $1 \mathrm{mg}$ of $\beta$-carotene); that is, those participants in the highest quartile of $\beta$-carotene intake (3.2-7.2 mg/d) had a mean increased of almost 1 point in their cognitive function scores compared to those in the lowest quartile $(0-0.9 \mathrm{mg} / \mathrm{d}), \quad(\beta=0.95$; $95 \%$ CI 0.52 to $1.11 ; p<0.001)$. None of the others antioxidants were associated to cognitive function.

Conclusions Higher intakes of $\beta$-carotene were associated to better scores of cognitive function in a low-income Brazilian population.

\section{P2-238 A HIGH FRUIT AND VEGETABLE INTAKE IS ASSOCIATED WITH A REDUCED RISK OF CATARACT IN THE SPANISH EUREYE STUDY}

doi:10.1136/jech.2011.142976j.71

\footnotetext{
1,2M Pastor-Valero, ${ }^{* 1,2} \mathrm{~J}$ Vioque, ${ }^{1,2}$ E M Navarrete-Muñoz, 'D G Monzo. ${ }^{1}$ Departamento de Salud Pública, Universidad Miguel Hernández, San Juan de Alicante, Spain; ${ }^{2}$ CIBER en Epidemiología y Salud Pública (CIBERESP), (CIBERESP), Spain
}

Introduction Cataract is among the major causes of vision impairment and blindness worldwide. Epidemiological studies support the role of antioxidants in the aetiology of cataract, but the evidence for one specific antioxidant over another is inconsistent. We examined the associations between cataract and fruit and vegetable intake and dietary and blood levels of carotenoids, vitamin A, C and E.

Methods Cross-sectional population-based study with 583 elderly $\geq 65$, from Alicante province, participants of the European multicentre EUREYE study. Cataracts were diagnosed using a slit-lamp examination. Energy-adjusted intake of antioxidant vitamins was estimated using a semi-quantitative food frequency questionnaire. Plasma concentrations of vitamin $\mathrm{C}$ were analysed by a colouri- metric method and carotenoids by a HPLC method. The associations between cataract and quartiles of fruit and vegetable intake and antioxidants were investigated using multiple logistic regression models.

Results After adjusting for other factors, participants in the highest quartile of fruit and vegetable intake ( $>575 \mathrm{~g} /$ day) had a reduced risk of cataract, $(\mathrm{OR}=0.42 ; 95 \% \mathrm{CI} 0.23$ to 0.79 ; p-trend $<0.001)$. Intakes of vitamin C of $143-408 \mathrm{mg} / \mathrm{d}$, and vitamin $\mathrm{E}$ of $9.3-10.7 \mathrm{mg} /$ day, showed a significant lower risk of cataract, $(\mathrm{OR}=0.34 ; 95 \% \mathrm{CI} 0.14$ to 0.82 ) and ( $O R=0.41 ; 95 \%$ CI 0.20 to 0.82 ), respectively. Plasma $\alpha$ tocopherol levels from $31.2 \mu \mathrm{mol} / 1$ were also associated with a decreased risk $(\mathrm{OR}=0.30 ; 95 \%$ CI 0.15 to 0.60$)$.

Conclusions High intake of fruit and vegetables, vitamin $\mathrm{E}$ and $\mathrm{C}$ was associated with a significantly decreased risk of cataract in this older Mediterranean population.

\section{P2-239 ASSOCIATIONS BETWEEN SEX HORMONES AND BONE MINERAL DENSITY AND BONE RESORPTION IN 50-YEAR- OLD MEN: THE NEWCASTLE THOUSAND FAMILIES STUDY}

doi:10.1136/jech.2011.142976j.72

${ }^{1} \mathrm{M}$ Pearce, ${ }^{*}{ }^{1} \mathrm{~A}$ Groom, ${ }^{1} \mathrm{C}$ Relton, ${ }^{2} \mathrm{~T}$ Pollard, ${ }^{3} \mathrm{~L}$ Parker, ${ }^{1} \mathrm{R}$ Francis. ${ }^{1}$ Newcastle University, Newcastle upon Tyne, UK; ${ }^{2}$ Durham University, Durham, UK; ${ }^{3}$ Dalhousie University, Halifax, Nova Scotia, Canada

Introduction While much research relating sex hormones to bone health has centred on oestrogen deficiency in postmenopausal women, far less is known regarding the potential for sex hormone levels to influence bone health in men. We investigated the influence of sex hormone concentrations on bone health in men at age 50 using data from the Newcastle Thousand Families Study.

Methods The study included 171 men who attended for DEXA scanning (giving measures of bone mineral density (BMD) for the hip and lumbar spine) and also gave blood samples allowing measurement of concentrations of testosterone, oestradiol, sex hormone binding globulin (SHBG), free androgen index (FAI), free oestrogen index (FEI), luteinising hormone (LH), follicle stimulating hormone $(\mathrm{FSH})$, free testosterone and serum $\beta$ C-telopeptide of type 1 collagen (CTX), a biochemical marker of bone resorption.

Results There were significant correlations between total hip BMD and FEI $(p=0.03)$, total spine BMD and SHBG $(p=0.006)$, FEI $(p=0.008)$ and FAI $(p=0.008)$ and serum CTX and free testosterone $(p=0.016)$. After adjustment for body weight the only associations that remained were between total spine BMD and FAI $(p=0.046)$ and between serum CTX and free testosterone $(p=0.014)$.

Conclusions Our results suggest that while there are associations between serum sex hormone concentrations and BMD, they are mostly explained by an adjustment for contemporary body weight. The inverse association between serum CTX and free testosterone is more robust, remaining significant after adjustment. This suggests that free testosterone levels are independently associated with bone resorption levels.

\section{P2-240 TIME TRENDS IN MORTALITY FROM CARDIOVASCULAR DISEASES AND CANCER IN PORTUGAL BETWEEN 1985 AND 2005}

doi:10.1136/jech.2011.142976j.73

M Pereira, ${ }^{*}$ B Peleteiro, A Azevedo, N Lunet. Department of Hygiene and Epidemiology, University of Porto Medical School; Cardiovascular R\&D Unit; Institute of Public Health of the University of Porto (ISPUP)., Porto, Portugal

Introduction We aim to describe time trends in death rates from cardiovascular diseases (CVD) and cancer in the Portuguese 